\title{
The Protective Effect of Sika Deer Antler Protein on Gentamicin-Induced Nephrotoxicity in Vitro and in Vivo
}

\author{
Hang Sun ${ }^{a}$ Huihai Yang ${ }^{a}$ Haonan Ruan ${ }^{a}$ Wei Li ${ }^{a}$ Xinhong $\mathrm{He}^{\mathrm{a}}$ \\ Lulu Wang $^{\mathrm{b}}$ Fangfang Liu ${ }^{\mathrm{b}}$ Jing Zhanga,b \\ aDepartment of Traditional Chinese Pharmacology, College of Traditional Chinese Medicine, Jilin \\ Agricultural University, Changchun, ${ }^{b}$ Changchun Science-Technology University, Changchun, China
}

\section{Key Words}

Sika deer antler protein $\cdot$ Oxidative stress $\cdot$ Apoptosis $\bullet$ Inflammation $\cdot$ Renal protection

\begin{abstract}
Background/Aims: Sika deer (Cervus nippon Temminck) antler is traditional animal medicine of renal protection in East Asia. This study measured the effect of sika deer antler protein (SDAPR) on gentamicin (GM)-induced cytotoxicity in HEK293 cells, and investigated the effect of SDAPR against GM-induced nephrotoxicity in mice. Methods: HEK293 cells viability and oxidative stress were measured in HEK293 cells while flow cytometry was used for apoptosis analysis. The acute kidney injury biomarkers, kidney injury molecule-1 (KIM-1), neutrophil gelatinase-associated lipocalin (NGAL) and cystatin c (Cys-C), were repeatedly measured by ELISA assay. ICR male mice were randomly assigned six groups: Control, GM with vehicle, single SDAPR, GM with SDAPR at three concentrations 50, 100, $200 \mathrm{mg} / \mathrm{kg} / \mathrm{d}$, p.o., $10 \mathrm{~d}$. GM was injected for 8 consecutive days ( $100 \mathrm{mg} / \mathrm{kg} / \mathrm{d}$, i.p.). Renal function, oxidative stress and levels of inflammatory factors were measured in vivo. Renal tissues were stained with $\mathrm{H} \& \mathrm{E}$ to observe pathological changes. Results: Pretreatment with SDAPR $(0.5-4.0 \mathrm{mg} / \mathrm{mL})$ significantly improved cell viability. Treatment with SDAPR could reduce KIM-1, NGAL and Cys-C activity. SDAPR could improve antioxidant defense and attenuated apoptosis on HEK293 cells. SDAPR also ameliorated GM-induced histopathologic changes, and decreased blood urea nitrogen (BUN) and serum creatinine (Cr). Additionally, SDAPR significantly regulated oxidative stress marker and interleukin-6 (IL-6), tumor necrosis factor- $\alpha$ (TNF- $\alpha$ ) inflammatory cytokines. Conclusion: These results show that SDAPR could be an effective dietary supplement to relieve GM-induced nephrotoxicity by improved antioxidase activity, suppressed inflammation, and inhibited apoptosis in vitro and vivo.




\section{Introduction}

GM is widely used and very effective aminoglycoside antibiotic. It usually used to treat gram-negativeinfection[1].GMeffectively linksto prokaryotic ribosomes, causemistranslation that protein synthesis is inhibited resulting in bacterial death [2]. Despite its low cost and rapid bactericidal action, serious complication such as nephrotoxicity and ototoxicity are important confining factors for the clinical application [3]. The clinical symptoms of GM nephrotoxicity are renal tubular injury and dysfunction of glomerular filtration. Meanwhile occurs in approximately $10-25 \%$ of patients show signs of nephrotoxicity with a single dose of GM [4]. Kidneys are essential functional organs which retain the blood clean and maintain the chemical balance. Its play important roles in maintaining electrolyte and water balance in the body. Then, kidney damage is considered to organism dysfunction [5]. Studies have shown that reactive oxygen species (ROS) play important roles in the process of kidney damage [6-7]. And occurrence of oxidative stress caused by alterations of redox homeostasis. Then, oxidative stress is increased in the kidney usually lead to inflammation and apoptosis and dysfunction of the kidney [8-9]. Moreover, oxidative stress is closely related to common disease such as hyperlipidemia and cancer [10-12].

Sika deer antler is one of the most important animal medicines and has been used for various functions, including tissue repair, anti-osteoporosis, antioxidant, and treatment bone-resorption diseases [13]. As a traditional medicine, sika deer antlers have been used in East Asia more than two thousand years, which could nourish Yin, tonify the kidney [14]. Previous studies also have suggested that sika deer antlers have bioactive components, such as protein, polysaccharides, phospholipids, amino acids, mineral elements, fatty acids [15]. Recently, previous studies show that the protein extract of Sika deer antlers could against cisplatin-induced cytotoxicity in HEK293 cells [16]. With this background, the objective of this study is to assess the renoprotective efficacy of SDAPR against GM nephrotoxicity and study the potential mechanisms of renal protection.

\section{Materials and Methods}

\section{Sample extraction}

Sika deer antler powder (200 g, lot No.20170726) was purchased from deer town (Changchun, China). The powder of sika deer antler (50.00 g) was put into $250 \mathrm{~mL}$ of water for $6 \mathrm{~h}$ at room temperature, and then was extracted by ultrasound device (KQ5200DB, Kunshan, China) at $60^{\circ} \mathrm{C}$ for $0.5 \mathrm{~h}, 3$ times. The extract solution was filtered and collected. The previous extract solution was precipitated by adding $4^{\circ} \mathrm{C}, 95 \%(\mathrm{v} / \mathrm{v})$ ethanol to a final concentration of $85 \%(\mathrm{v} / \mathrm{v})$ and then let it stand for $12 \mathrm{~h}$ at $4^{\circ} \mathrm{C}$. Then, the precipitate was collected by centrifugation ( $8000 \mathrm{rpm}, 15 \mathrm{~min}$ ). The ethanol was removed from the collected precipitate by using a rotary evaporator $\left(50 \mathrm{rpm}, 60^{\circ} \mathrm{C}\right)$, (R205, Shanghai, China). Finally the precipitate was dissolved in water and solution of precipitate was freeze-dried to obtain purified antler protein powder (SDAPR). SDAPR content was $92.60 \%$ using Bradford method.

\section{Cell culture}

Vendor authenticated immortalized human embryonic kidney 293 cells (HEK293) were purchased from American Type Culture Collection and obtained from the Laboratory of Molecular Biological (Jilin Agricultural University, China). HEK293 cells were cultured with minimum essential media (DMEM, Hyclone, USA) and supplemented with 10\% fetal bovine serum (FBS, Hycolne, USA) and 1\% streptomycin/ penicillin $(100 \mathrm{U} / \mathrm{mL})$ (Solarbio, China). The cells were cultured in a $37^{\circ} \mathrm{C}$ humidified incubator $\left(5 \% \mathrm{CO}_{2}\right)$ (SELECTA, Spain) [17].

\section{Cytotoxicity assessment and kidney injury biomarker detect assays}

The HEK293 cells were seeded in 96-well plates and then pretreat with SDAPR at different concentrations for $24 \mathrm{~h}$. Then exposed to gentamicin ( $3 \mathrm{mg} / \mathrm{mL}, 50 \mu \mathrm{L} /$ well) [18], (Changchun Amendment Pharmaceutical Co. Ltd. China). After treatment for $24 \mathrm{~h}, 20 \mu \mathrm{L}$ MTT (Harihar et al. 2014) (5 mg/mL, Amersco, USA) was added into the wells and HEK293 cells were cultured at $37^{\circ} \mathrm{C}$ for additional $4 \mathrm{~h}$. Then, medium with MTT solution was abandoned and $200 \mu \mathrm{L}$ DMSO (Shanghai Civi Chemical Technology, China) 


\section{Cellular Physiology Cell Physiol Biochem 2018;50:841-850 and Biochemistry \begin{tabular}{l|l} 
DOI: 10.1159/000494471 & $\begin{array}{l}\text { (c) } 2018 \text { The Author(s). Published by S. Karger AG, Basel } \\
\text { www.karger.com/cpb }\end{array}$
\end{tabular} \\ Sun et al.: Sika Deer Antler Protein Against Gentamicin Nephrotoxicity}

was added into each well, and the plates were slightly and horizontally agitated for 5 - 10 min. Finally, 96well plates were read at $490 \mathrm{~nm}$ using microplate reader (Nano, Germany). To determine whether low and high doses of SDAPR could induce renal injury makers, cell culture supernatants were applied into KIM1, NGAL and Cys-C pre-coated plates and according to the manufacturer's instructions (Shanghai meilian biotech. China). The absorbance was determined in lysates at $450 \mathrm{~nm}$ using a microplate reader.

\section{Oxidative stress markers}

The cells were disrupted with ultrasound. Then, enzyme solution of cell was collected by centrifugation at $4^{\circ} \mathrm{C}(8000 \mathrm{rpm}, 10 \mathrm{~min})$ and was measured to oxidative stress markers level, including superoxide dismutase (SOD), lactate dehydrogenase (LDH), glutathione (GSH), and malondialdehyde (MDA). Oxidative stress markers were determined according to the commercial kit instructions (Nanjing Jiancheng Biotech. China) and measured with a microplate reader (Nano, Germany).

\section{Flow cytometry analysis}

The rate of apoptosis was determined by flow cytometry using the Annexi V-FITC/PI apoptosis kit (Solarbio, China). HEK293 cells were assigned five groups. Control group: DMEM (vehicle of PBS) was added; GM group: received gentamicin $(3.00 \mathrm{mg} / \mathrm{mL})$; Single SDAPR: SDAPR $(4.00 \mathrm{mg} / \mathrm{mL})$; GM+SDAPR group: received GM $(3.00 \mathrm{mg} / \mathrm{mL})+$ SDAPR $(2.00 \mathrm{mg} / \mathrm{mL})$, received GM $(3.00 \mathrm{mg} / \mathrm{mL})+$ SDAPR $(4.00 \mathrm{mg} /$ $\mathrm{mL}$ ). After treatment for $24 \mathrm{~h}$, HEK293 cells were collected and washed 3-5 times with PBS, then stained with Annexin V-FITC ( $5 \mu \mathrm{L})$ for $10 \mathrm{~min}$. Then, PI ( $5 \mu \mathrm{L})$ was added for $5 \mathrm{~min}$ in the dark. A total of 10, 000 HEK293 cells in each sample were detected by flow cytometer (Accuri C6, BD Biosciences, USA).

\section{Animals and experimental protocol}

In this study, we followed the Guidelines for Animal Experimentation, which is approved by the Institutional Animal Ethic Committee of Department of Biochemistry, Jilin Agricultural University, Changchun, China. ICR male mice $(n=42)$ weighing $20 \pm 2$ g were used to evaluate the protective effect of the SDAPR against gentamicin-induced nephrotoxicity, and were purchased from the Yisi Laboratory Animal Technology Co. Ltd. (SCXY-2011-0004). Mice were housed under fixed temperature $\left(28 \pm 2^{\circ} \mathrm{C}\right)$ and humidity $(60 \pm 5 \%)$ conditions with a standard light $(12 \mathrm{~h} /$ dark $)$. Mice were randomly divided into six groups of 7 animals each. Control group, the mice received distilled water (p.o.) for 10 consecutive days and were intraperitoneally (i.p.) injected with normal saline. GM group, received distilled water for 10 consecutive days and GM (100 mg/kg/day; i.p.) from the third day to the tenth day [19]. Single SDAPR, received SDAPR (200 mg/kg/day; p.o.) for 10 consecutive days and were intraperitoneally (i.p.) injected with normal saline. GM+SDAPR group: received a low-dose (50 mg/kg/day; p.o.), a middle-lose (100 mg/kg/day; p.o.), or a high-dose (200 mg/kg/day; p.o.), respectively of SDAPR solution for 10 consecutive days and GM (100 mg/ $\mathrm{kg}$ /day; i.p.) dissolved with saline as a single intraperitoneal injection from the third day to the tenth day. On the tenth day, before mice were euthanized, blood samples were collected from ophthalmic veins and renal samples were collected for subsequent analysis. One kidney was removed to determine histological analysis; the other was stored at $-80^{\circ} \mathrm{C}$ for biochemical analysis.

\section{Renal function and kidney index in mice}

In the treatment period, the weight of mice was weighted. After the mice were sacrificed, the kidneys were quickly excised, cleaned and weighted. Then, the kidney index was calculated, kidney index $=[\mathrm{kidney}$ weight $(\mathrm{g}) /$ body weight $(\mathrm{g})] \times 100$

The extent of renal functions in mice was assessed by measuring blood urea nitrogen (BUN) and serum creatinine (Cr) levels. Blood samples were collected into micro-centrifuge tube. Then, it's centrifuged (3500 $\mathrm{rpm}, 15 \mathrm{~min}$ ) to separate the serum. Kidney function indexes levels were estimated in the serum using the commercial kit (Nanjing Jiancheng Biotech. Co. Ltd. Nanjing, China).

\section{Measurement of oxidative stress markers in mice}

The super oxide dismutase (SOD), catalase (CAT), glutathione (GSH), and malondialdehyde (MDA) in renal tissues were determined, according to the commercial kit instructions (Nanjing Jiancheng Biotech. Co. Ltd. Nanjing, China, Model: SOD A001-3; CAT A007-1-1; GSH A006-2 and MDA A003-1) and the microplate reader (Nano, Germany).

\section{ELISA assay}

After the experimental period, inflammation markers of interleukin-6 (IL-6) and tumor necrosis factor (TNF- $\alpha$ ) in renal tissues was examined by using mouse ELISA kits (BOSTER, USA, EK0411 and EK0527) following manufacturer's instructions. The IL-6 and TNF- $\alpha$ level of tissue were expressed as pg/mg of 


\section{Cellular Physiology Cell Physiol Biochem 2018;50:841-850 \\ \begin{tabular}{ll|l} 
and Biochemistry & Dublished online: 23 October 2018 & $\begin{array}{l}\text { (c) } 2018 \text { The Author(s). Published by S. Karger AG, Basel } \\
\text { www.karger.com/cpb }\end{array}$
\end{tabular}}

Sun et al.: Sika Deer Antler Protein Against Gentamicin Nephrotoxicity

Histological analysis

The renal tissue of right kidneys from each mouse was quickly fixed in 10\% neutral-buffered formalin for histopathology. The kidneys were progressively dehydrated, embedded in paraffin, cut into 5 - $\mu \mathrm{m}$ sections, and stained with the hematoxylin and eosin (H\&E) for histological inspection. Finally, kidney tissue sections were observed by light microscopy (Leica, Germany).

\section{Statistical analysis}

All values were expressed as mean \pm SD and analyzed using SPSS version 19.0 statistical programs. One-way analysis of variance (ANOVA) was used to compare different groups. $P<0.05$ and $P<0.01$ were used as the criterion for statistical significance.

\section{Results}

Cytotoxic evaluation of GM and SDAPR in HEK293 cells and effects on KIM-1 molecules, NGAL, and Cys-C

When HEK293 cells were exposed to $3 \mathrm{mg} / \mathrm{mL} \mathrm{GM}$ for $24 \mathrm{~h}$, the percentage of cellular viability was $51.10 \%(P<0.01)$. The HEK293 cell viability was decreased to $48.13 \%(P<$ 0.01 ) of the control value after treatment with $3 \mathrm{mg} / \mathrm{mL}$ GM. The decreased cell viability of HEK293 cells caused by GM was significantly recovered after treatment with SDAPR in a dose-dependent manner. SDAPR $(4 \mathrm{mg} / \mathrm{mL})$ ameliorated GM-induced cytotoxicity and improved cell viability to $34.88 \%$ compared with GM group $(P<0.01)$ (Fig. 1A). Additionally, we examined the effect of SDAPR on activity of the biomarkers: KIM-1, NGAL and Cys-C, which are kidney injury molecules. The activity levels of KIM-1, NGAL and Cys-C levels were significantly increased than those of the control group. Conversely, SDAPR pretreatment significantly ameliorated the kidney injury biomarkers which reduced levels of KIM-1 (Fig. 1 B), NGAL (Fig. 1 C) and Cys-C (Fig. 1 D) compared with GM group.

\section{Effects of SDAPR treatment GM-induced oxidative stress}

Compared with control group, SOD as important endogenous enzymes of antioxidant defense, was reduced in GM group (Fig. 2A). And GSH levels were decreased in GM group (Fig. 2B). MDA and LDH levels are significantly increased (Fig. 2C, 2D). Pretreatment with SDAPR significantly decreased the MDA and LDH levels and increased the activity of antioxidant enzymes compared with the GM group $(P<0.01)$.

\section{Effects of SDAPR on HEK293 cells apoptosis}

For determine whether SDAPR ameliorate cytotoxicity of HEK293 cells is associated with the restrained activation of apoptosis, we proceed the following investigation. HEK293 cells significantly increased the total percentage of apoptotic to $54.77 \%$ when treating $3 \mathrm{mg} / \mathrm{mL}$ GM for $24 \mathrm{~h}$, compared with the control group $(P<0.01)$ (Fig. 3). However, treatment with SDAPR $(2.00$ and $4.00 \mathrm{mg} / \mathrm{mL})$ resulted in a significantly decrease from $56.31 \%$ to $33.72 \%$ or $10.30 \%(P<0.01)$. The results show that although GM treatment resulted in increased apoptosis, SDAPR play improved effect in GM induced cell apoptosis.

\section{Effect of SDAPR treatment on GM-induced kidney dysfunction and kidney index}

As shown in Table 1, GM produced significant weight and creatinine clearance reductions, and kidney index increase compared with the control group. Compared with GM group, the mice that pretreatment on SDAPR significantly show higher weights and creatinine clearance, and decrease the kidney index. Also, administration of single SDAPR has no effect on these parameters compared with the control mice.

In the comparison of serum biochemical analyses, GM-injected mice showed signs of nephrotoxicity. $\mathrm{Cr}$ and BUN of serum levels were significantly increased than those of the control group. Conversely, SDAPR pretreatment significantly ameliorated the kidney functions which reduced levels of $\mathrm{Cr}$ and BUN compared with GM group in a dose-dependent manner (Fig. 4). 
Fig. 1. Effect of SDAPR on HEK293 cells viability and KIM-1 molecules, NGAL, and Cys-C. (A) Cytotoxicity was measured by MTT assay. (B, C and D) KIM-1, NGAL and Cys-C were measured by ELISA assay.

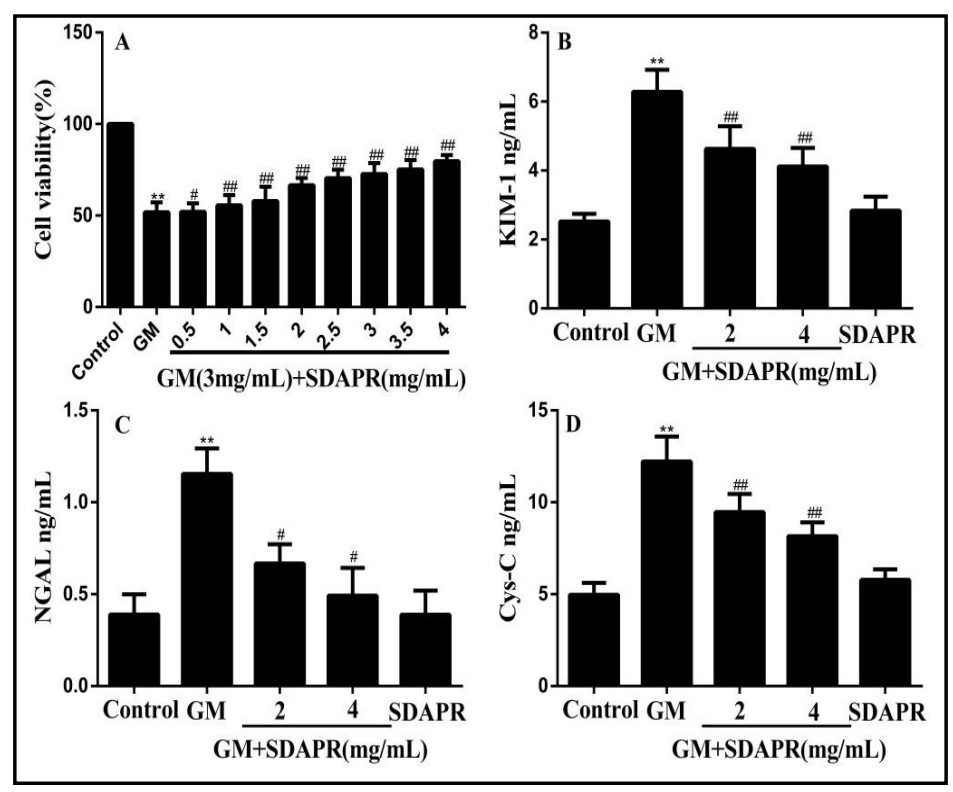

Fig. 2. Effect of SDAPR pretreatment on GM-induced oxidative stress parameters in HEK293 cells. Values are expressed as means $\pm S D(n=6) .{ }^{* *} \mathrm{P}<0.01$ vs. Control group; ${ }^{\#} \mathrm{P}<0.05$, ${ }^{\# \#} \mathrm{P}<0.01$ vs. GM group.
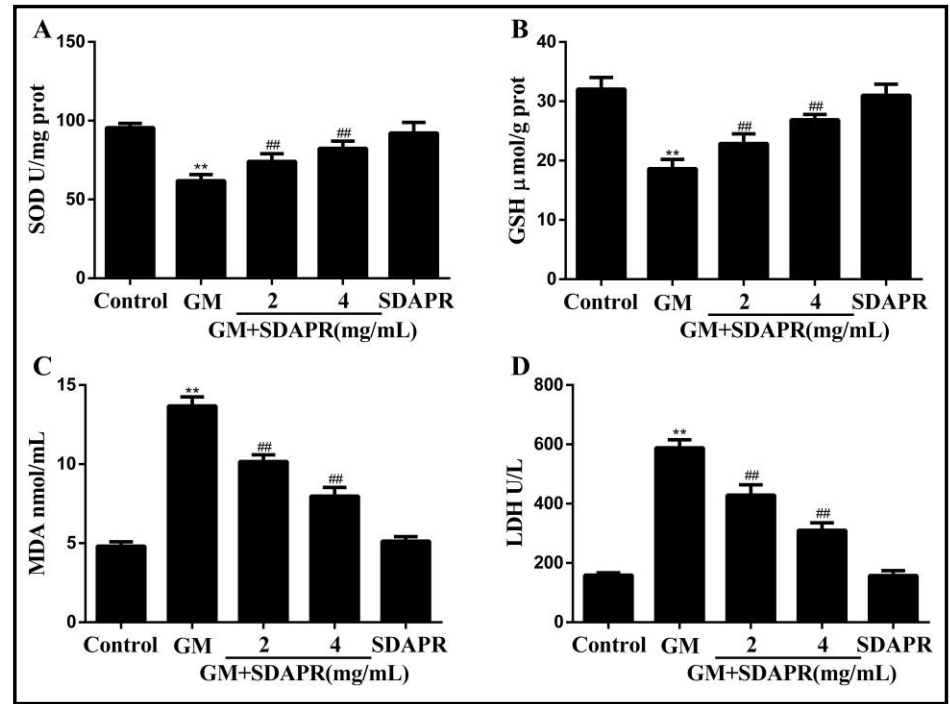

Effect of SDAPR treatment on GM-induced oxidative stress in mice

GM-induced nephrotoxic mice showed significantly increased lipid peroxidation products (MDA) in kidney tissue (Fig. 5C). Meanwhile the activities of antioxidant enzymes were significantly decreased such as SOD, GSH and CAT $(P<0.01)$. However, Pretreatment with SDAPR significantly reduced the MDA level and increased the activity of antioxidant enzymes compared with the GM group $(P<0.01)$ (Fig. 5A, B, D). This result indicates that SDAPR has anti-oxidative effects to GM-induced oxidative stress damage in vivo.

\section{Effect of SDAPR treatment on GM-induced inflammation}

As shown in Fig. 6A and B, We evaluated the release levels of inflammatory cytokine in each group renal tissues by ELISA assay. GM induced a significantly increase in IL-6 and TNF- $\alpha$ levels when compared with control group $(P<0.01)$. Conversely, SDAPR significantly decreased GM-induced inflammatory cytokine production, compared with GM group $(P<$ $0.01)$. SDAPR could down regulate IL- 6 and TNF- $\alpha$ release levels while has potential antiinflammatory activity.

\section{KARGER}




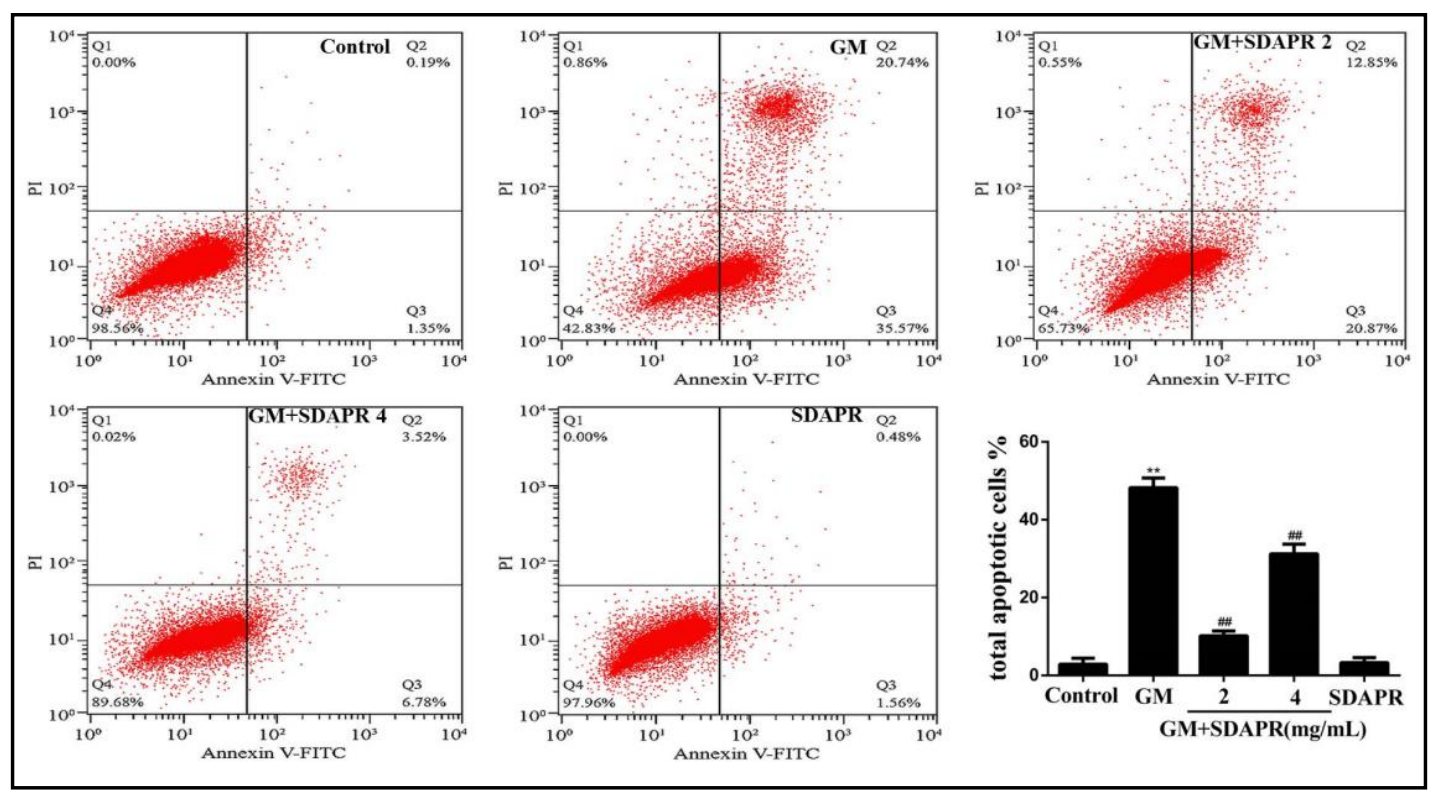

Fig. 3. Effect of SDAPR on apoptosis induction in GM treated HEK293 cells. (A) Cultured HEK293 cells were exposed to GM or pretreated with SDAPR for $24 \mathrm{~h}$. Flow cytometry was applied to analyze Annexin V-FITC/ PI double stained cells. (B) Bar graphs showing the percentage of total apoptotic cells in HEK293 cells.

Table 1. Effect of SDAPR treatment on GM-induced alterations in body weight, kidney weight and kidney index. BW: body weight; KW: kidney weight; Ccr : creatinine clearance; Kidney index=[kidney weight (g)/ body weight $(\mathrm{g})] \times 100$

\begin{tabular}{|c|c|c|c|c|}
\hline Parameter & $\begin{array}{l}\text { BW } \\
\text { (g) }\end{array}$ & $\begin{array}{c}\mathrm{KW} \\
(\mathrm{mg})\end{array}$ & Ccr (mL/min) & Kidney index \\
\hline Control & $32.87 \pm 1.89$ & $250.01 \pm 20.36$ & $2.02 \pm 0.14$ & $0.76 \pm 0.09$ \\
\hline $\mathrm{GM}(100 \mathrm{mg} / \mathrm{kg})$ & $27.39 \pm 1.71^{* *}$ & $311.43 \pm 32.12^{* *}$ & $1.49 \pm 0.12^{* *}$ & $1.14 \pm 0.16^{* *}$ \\
\hline SDAPR $(200 \mathrm{mg} / \mathrm{kg})$ & $31.89 \pm 1.49$ & $252.73 \pm 20.15$ & $2.08 \pm 0.09$ & $0.78 \pm 0.10$ \\
\hline $\mathrm{GM}+\mathrm{SDAPR}(50 \mathrm{mg} / \mathrm{kg})$ & $29.09 \pm 1.14^{\#}$ & $281.43 \pm 26.23^{\#}$ & $1.72 \pm 0.11^{\#}$ & $0.97 \pm 0.10^{\#}$ \\
\hline GM+SDAPR $(100 \mathrm{mg} / \mathrm{kg})$ & $29.36 \pm 1.33^{\#}$ & $267.14 \pm 30.14^{\# \#}$ & $1.83 \pm 0.13^{\# \#}$ & $0.91 \pm 0.13^{\#}$ \\
\hline $\mathrm{GM}+\mathrm{SDAPR}(200 \mathrm{mg} / \mathrm{kg})$ & $30.43 \pm 1.46^{\# \#}$ & $255.71 \pm 33.35^{\# \#}$ & $1.91 \pm 0.15^{\# \#}$ & $0.84 \pm 0.10^{\# \#}$ \\
\hline
\end{tabular}

Fig. 4. Effect of SDAPR treatment on GM-induced alteration blood BUN and serum $\mathrm{Cr}$ levels in mice.
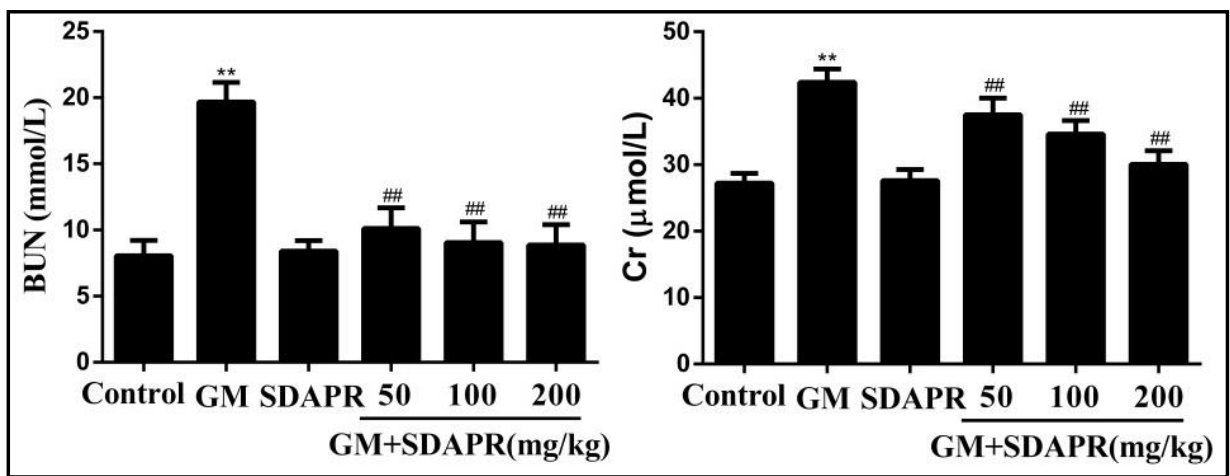

\section{Histopathological examination}

H\&E staining was conducted on tissues sections to evaluate level of kidney damage. As shown in Fig. 7, renal tissues showed a normal structure in the renal tubules and glomeruli (Fig. 7A). However, we observed severe tubuloiontrstitial injuries including cystic dilatation of tubules, cellular vacuolization, and cast formation in the GM-exposed kidneys (Fig. 
Fig. 5. Effect of SDAPR treatment on GM-induced the oxidative stress parameters in mice.
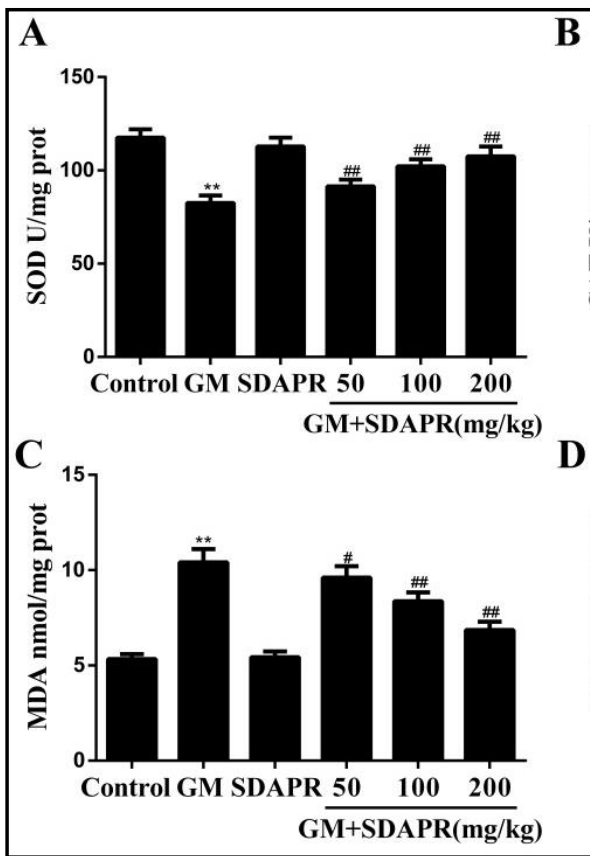

B
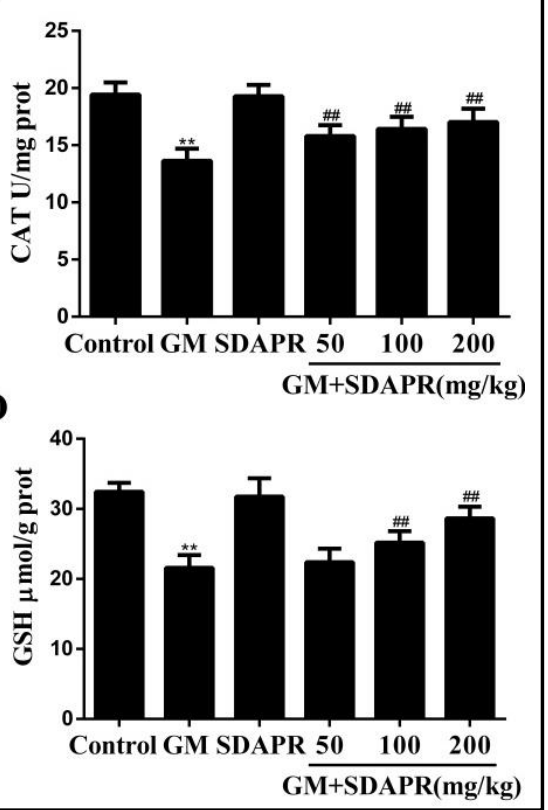

Fig. 6. Effect of SDAPR on GM-induced inflammatory c y t o k i n e s parameters in kidney tissues of mice.

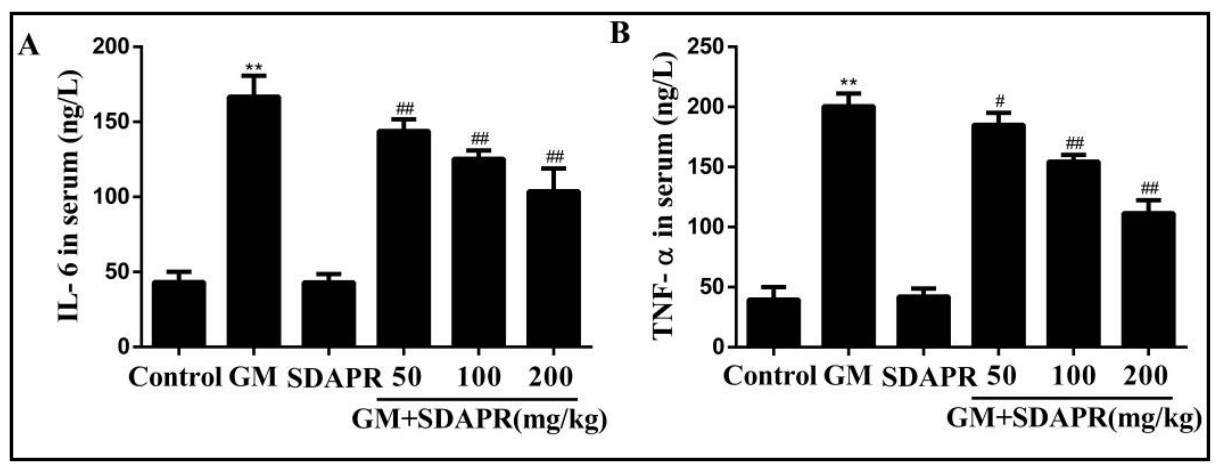

Fig. 7. Histo-pathological changes of kidney tissues.

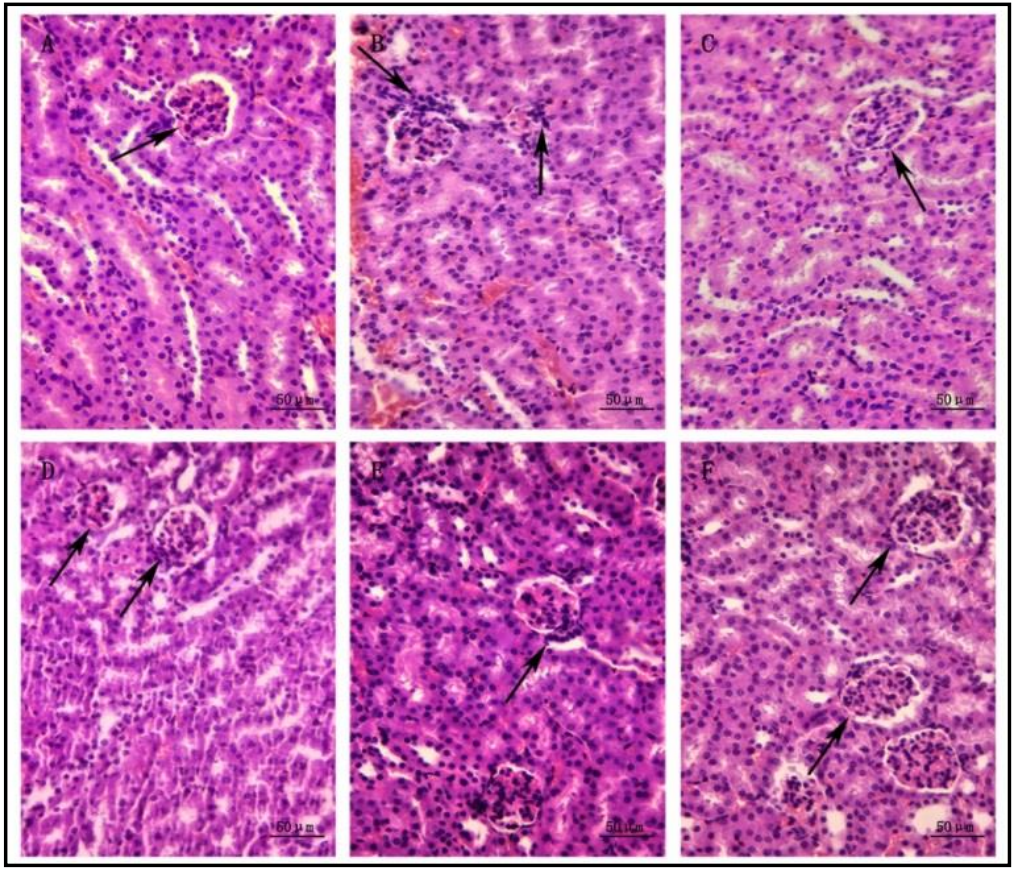




\section{Cellular Physiology Cell Physiol Biochem 2018;50:841-850

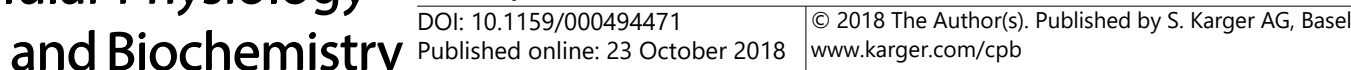

7B). Compared with GM group, SDAPR significantly ameliorate the GM-induced changes of renal histopathology in a dose-dependent manner (Fig. 7D, E, F). Also, administration of single SDAPR has no effect on these parameters compared with the control mice (Fig. 7C) According Ridit analysis, the grade of renal tubular necrosis significantly increased when compare with control group. However, Pretreatment with SDAPR significantly reduced the grade of renal tubular necrosis compared with the GM group (Table 2). tubular necrosis grade
Table 2. Effect of SVPr on pathological changes of kidney injury mice induced by GM analyzed by renal

\begin{tabular}{lllllll}
\hline \multirow{2}{*}{ Group } & \multicolumn{7}{c}{ Renal tubular necrosis grade } & \multirow{2}{*}{ Ridit analysis } \\
\hline Normal control & 0 & 1 & 2 & 3 & 4 & \\
GM & 6 & 1 & 0 & 0 & 0 & 0.13 \\
SDAPR & 0 & 0 & 1 & 3 & 3 & $0.82^{*}$ \\
GM+SVPr 50mg-kg-1 & 6 & 1 & 0 & 0 & 0 & 0.13 \\
100 mg.kg-1 & 0 & 1 & 2 & 2 & 2 & 0.71 \\
$200 \mathrm{mg} \cdot \mathrm{kg}^{-1}$ & 0 & 2 & 3 & 1 & 1 & 0.61 \\
\hline
\end{tabular}

\section{Discussion}

Nephrotoxicity occurs when the kidney cannot properly detoxify and excrete due to the decreased kidney function in response to toxicants [20]. The recent studies indicated that ROS plays important roles in the process of GM-induced nephrotoxicity [21-22]. Therefore, antioxidants as inhibitor of ROS are considered to be an important therapeutic approach for kidney disease. However, GM-induced nephrotoxicity is a significant and non-ignorable clinical problem. Hence, we need to investigate the protective potential and molecular mechanisms of SDAPR on the nephrotoxicity caused by GM, such as oxidative stress, inflammation and apoptosis to evaluate its clinical application of kidney diseases.

We performed in vitro test to confirm the protective effect of SDAPR on human-derived kidney cells, such as immortalized human embryonic kidney 293 cells. The kidney cell protection assay conditions were established using the HEK293 cell line, which is commonly used to evaluate nephrotoxicity [23]. The potent protective effect by ameliorating reduced cell viability, oxidative stress, apoptosis and acute kidney injury biomarkers (KIM-1, NGAL and Cys-C) due to GM was observed pretreatment with SDAPR. Then, we further examined the effect of SDAPR on GM-induced nephrotoxicity in mice.

In previous studies, we found an effect which GM administration could significantly increase levels of serum BUN and Cr after GM injected [24-26]. Conversely, the higher BUN and $\mathrm{Cr}$ as an indicator of kidney dysfunction in GM-induced mice recovered to normal levels after co-treatment with SDAPR. Oxidative stress is an important factor that leads to GM nephrotoxicity. However, the incomplete reduction of molecular oxygen leads to the formation of ROS and free radicals [27-28]. It is reported that ROS play vital factor in GMinduced nephrotoxicity [29]. The role of oxidative was examined by estimating the levels of oxidative stress marker, such as SOD, GSH and CAT. Additionally, MDA is regard as commonly used indicator of oxidative stress and could evaluate level of bio-membrane damage. ROS generated during normal cellular processes are detoxified by endogenous enzymes, such as SOD, GSH and CAT. However, an imbalance between oxidation and reduction processes result in excessive ROS were generated by GM. In this study, the normal mice treat with GM 8 consecutive days lead to a phenomenon which antioxidant enzyme activity was inhibited. Treatment of GM nephrotoxicity in mice with SDAPR markedly supplement the reduce levels of SOD, GSH, CAT and decreased MDA, which may be explained by the ROS and free radical scavenging activity of SDAPR.

In the previous investigation, pro-inflammatory cytokines increased expression at the gene and protein levels after GM injection [30]. There are these inflammatory cytokines lead to nephrotoxicity, such as IL- 6 and TNF- $\alpha$. Meanwhile, the generations of inflammatory cytokines were inhibited could attenuate renal tissue damage by GM. Our data showed that SDAPR significantly reduced the levels of IL- 6 and TNF- $\alpha$ in kidney tissue.

On histopathological examination, previous studies show that tubulointerstitial injuries including cystic dilatation of tubules, cellular vacuolization, and cast formation in the GM- 


\section{Cellular Physiology Cell Physiol Biochem 2018;50:841-850

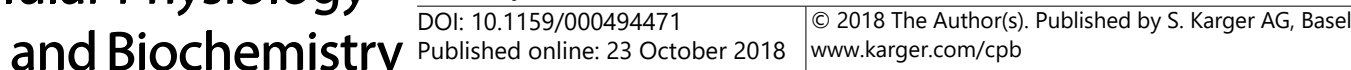

exposed kidneys. However, we observed that SDAPR significantly ameliorated GM-induced renal structure injury in mice.

\section{Conclusion}

In summary, HEK293 cells damage induced by oxidative stress and apoptosis were significantly inhibited by the treatment with SDAPR. In addition, the renal dysfunction of GM-induced mice markedly ameliorated by SDAPR. Hence, the protective mechanisms were associated with improvement of antioxidant activity, inhibition of inflammation and apoptosis. Taken together, our results demonstrate that SDAPR exerted a renal protective effect in GM-induced mice, and can be an effective supplement to relieve GM-induced nephrotoxicity in vivo and vitro.

\section{Acknowledgements}

This work was supported by the Jilin Science and Technology Development Program of China (Grant no. 20180414071GH).

\section{Disclosure Statement}

The authors declared no conflicts of interest.

\section{References}

1 Ali BH: Agents ameliorating or augmenting experimental gentamicin nephrotoxicity: some recent research. Food Chem. Toxicol 2003;41:1447-1452.

2 Sundin DP, Sandoval R, Molitoris BA: Gentamicin inhibits renal protein and phospholipid metabolism in rats: implications involving intracellular trafficking. J. Am. Soc. Nephrol 2001;12:114-123.

-3 Ali BH, Al ZM, Blunden G: Experimental gentamicin nephrotoxicity and agents that modify it: a mini-review of recent research. Basic Clin Pharmacol Toxicol 2011;109:225-232.

4 Liu Y, Ji P, Lv H, Qin Y, Deng L: Gentamicin modified chitosan film with improved antibacterial property and cell biocompatibility. Int J Biol Macromol 2017;98:550-557.

5 Li X, Hassoun HT, Santora R, Rabb H: Organ crosstalk: the role of the kidney. Curr Opin Crit Care 2009;15:481-487.

6 Pasqualotto FF, Sharma RK, Kobayashi H, Nelson DR, Thomas AJ, Agarwal A: Oxidative Stress in Normospermic Men Undergoing Infertility Evaluation. J Androl 2001;22:316-322.

-7 Rao M, Gangadharan B: Antioxidative potential of melatonin against mercury induced intoxication in spermatozoa in vitro. Toxicol in vitro 2008;22:935-942.

8 Heyman SN, Rosen S, Rosenberger C: A role for oxidative stress. Contrib to Nephrol 2011;174:138-148.

-9 Manucha W, Vallés PG: Apoptosis modulated by oxidative stress and inflammation during obstructive nephropathy. Inflamm \& Allergy Drug Targets 2012;11:303-312.

10 Li J M, Shah AM: ROS generation by nonphagocytic NADPH oxidase: potential relevance in diabetic nephropathy. J Am Soc Nephrol 2003;14:S221-226.

11 Hotamisligil GS: Endoplasmic reticulum stress and the inflammatory basis of metabolic disease. Cell 2010;140:900-917.

12 Chung HW, Lim JH, Kim MY, Shin SJ, Chung S, Choi BS, Kim YS, Park CW, Chang YS: High-fat diet-induced renal cell apoptosis and oxidative stress in spontaneously hypertensive rat are ameliorated by fenofibrate through the PPAR $\alpha$-FoxO3a-PGC-1 $\alpha$ pathway. Nephrol Dia Transplant 2012;27:2213-2225.

13 Kim JB, Bak SG, Jo HG, Cheong SH: Chemical compositions and antioxidant properties of enzymatic hydrolysates from velvet antler in elk (Cervus elaphus canadensis). Res J Pharm Biomed Chem 2016;3:2648-2654. 


\section{Cellular Physiology Cell Physiol Biochem 2018;50:841-850 \begin{tabular}{l|l|l} 
DOI: 10.1159/000494471 & $\begin{array}{l}\text { O } 2018 \text { The Author(s). Published by S. Karger AG, Basel } \\
\text { www.karger.com/cpb }\end{array}$
\end{tabular}}

Sun et al.: Sika Deer Antler Protein Against Gentamicin Nephrotoxicity

14 Sui Z, Zhang L, Huo Y, Zhang Y: Bioactive components of velvet antlers and their pharmacological properties. J Pharmaceut Biomed 2014;87:229-240.

15 Takatsuki S: The effects of sika deer (Cervus nippon) on the growth of Pleioblastus chino. Japanese J Ecol 1980;30:1-8.

16 Yang H, Li W, Wang L, He X, Sun H, Zhang J: The Proteins from Sika deer antler as potential modulators on cisplatin-induced cytotoxicity in human embryonic kidney 293 cells. Nat Prod Res 2017;1-5.

17 Zhang B, Peng X, Li G, Xu Y, Xiao X, Wang Q: Oxidative stress is involved in Patulin induced apoptosis in HEK293 cells. Toxicon 2015;94:1-7.

18 Hauschke M, Roušarová E, Flídr P, Čapek J, Libra A, Roušar T: Neutrophil gelatinase-associated lipocalin production negatively correlates with HK-2 cell impairment: Evaluation of NGAL as a marker of toxicity in HK-2 cells. Toxicol in vitro 2017;39:52-57.

19 Mahmoud YI: Kiwi fruit (Actinidia deliciosa) ameliorates gentamicin-induced nephrotoxicity in albino mice via the activation of Nrf2 and the inhibition of NF- $\kappa$ B (Kiwi \& gentamicin-induced nephrotoxicity). Biomed Pharmacother 2017;94:206-218.

20 Sun YK, Moon A: Drug-induced nephrotoxicity and its biomarkers. Biomol Ther 2012;20:268-272.

-21 El-Kashef DH, El-Kenawi AE, Suddek GM, Salem H: Protective effect of allicin against gentamicin-induced nephrotoxicity in rats. Int Immunopharmacol 2015;29:679-686.

-22 Zhu QY, Hackman RM, Ensunsa JL, Holt RR, Keen CL: Antioxidant activities of oolong tea. J Agric Food Chem 2002;50:6929-6934.

23 Raghubeer S, Nagiah S, Chuturgoon AA: Acute ochratoxin a exposure induces inflammation and apoptosis in human embryonic kidney (HEK293) cells. Toxicon 2017;137:48-53.

24 Kandemir FM, Ozkaraca M, Yildirim BA, Hanedan B, Kirbas A, Kilic K, Aktas E, Benzer F: Rutin attenuates gentamicin-induced renal damage by reducing oxidative stress, inflammation, apoptosis, and autophagy in rats. Renal Failure 2015;37:518-525.

-25 Chashmi NA, Emadi S, Khastar H: Protective effects of hydroxytyrosol on gentamicin induced nephrotoxicity in mice. Biochem Bioph Res Co 2017;482:1427-1429.

26 Yang H, Li W, Wang L, Li W, Sun H, He X, Zhang J: The Protective Effects of Sika Deer Antler Protein on Cisplatin-Induced Nephrotoxicity. Cell Physiol Biochem 2017;43:395-404.

27 Tortorici MA, Nolin TD: Kidney function assessment and its role in drug development, review and utilization. Expert Rev Clin Pharmacol 2014;7:523-532.

28 Ansari MA, Raish M, Ahmad A, Ahmad SF, Mudassar S, Mohsin K, Shakeel F, Korashy MK, Bakheet SA: Sinapic acid mitigates gentamicin-induced nephrotoxicity and associated oxidative/nitrosative stress, apoptosis, and inflammation in rats. Life Sci 2016;165:1-8.

29 Ali BH, Mousa HM: Effect of dimethyl sulfoxide on gentamicin-induced nephrotoxicity in rats. Hum Exp Toxicolo 2001;20:199-203.

-30 Quirós Y, Blanco-Gozalo V, Sanchez-Gallego JI, López-Hernandez FJ, Ruiz J, Obanos MP, López-Novoa JM: Cardiotrophin-1 therapy prevents gentamicin-induced nephrotoxicity in rats. Pharmacol Res 2016;107:137-146. 